\title{
Regional Scale Dynamic Prediction of Energy Ecological Footprint and Its Influencing Factors
}

\author{
Luyun Liu', Jian Zheng" ${ }^{2}$, Guo Li ${ }^{1}$, , Yan Wang ${ }^{1}$ \\ ${ }^{1}$ School of Landscape Architecture, Central South University of Forestry and Technology, Changsha, China \\ ${ }^{2}$ School of Architecture, South China University of Technology, Guangzhou, China
}

Email address:

56508178@qq.com (Luyun Liu), 50377905@qq.com (Guo Li)

${ }^{*}$ Corresponding author

\section{To cite this article:}

Luyun Liu, Jian Zheng, Guo Li, Yan Wang. Regional Scale Dynamic Prediction of Energy Ecological Footprint and Its Influencing Factors. International Journal of Environmental Protection and Policy. Vol. 7, No. 1, 2019, pp. 17-23. doi: 10.11648/j.ijepp.20190701.13

Received: December 6, 2018; Accepted: February 20, 2019; Published: March 8, 2019

\begin{abstract}
The regional energy ecological footprint is an important evaluation index which can reveal the energy consumption on regional environmental pressure and sustainable development. First, the study relied on EEF (energy ecological footprint) method to calculate the ecological footprint, the energy ecological footprint and the ecological capacity. While STIRPAT model was applied to examine the relationship between the regional populations scale, the economic level, the industrial structure, the energy utilization technology and the energy ecological footprint. Grey prediction model was used to predict the development tendency of the energy ecological footprint in the next 10 years. The data were elicited from statistical data of regional energy consumption. The energy ecological footprint was increased to $0.3437 \mathrm{ghm}^{2} / \mathrm{person}$ from $0.1234 \mathrm{ghm}^{2} /$ person during 2006-2015 in Xiangtan region. Though the energy capacity per capita increased slightly, the energy ecological footprint was kept in deficit. The level was increased to $0.2504 \mathrm{ghm}^{2} /$ person from $0.073 \mathrm{ghm}^{2} / \mathrm{person}$. The ecological pressure of the energy ecological footprint was very large. Among the influencing factors, the industrial structure contributes the most to explain the energy ecological footprint, followed by the population scale and the GDP per capita. The influence of the energy strength was minimal. The indices of energy ecological footprint, energy capacity and ecological pressure increased to $1.1205,0.1246$ and $8.9013 \mathrm{ghm}^{2} /$ person, respectively. The dynamic scale of energy ecological footprint and the analysis of the influencing factors can provide a theory for sustainable development of society-economy-resources and environment.
\end{abstract}

Keywords: Energy Ecological Footprint, Ecological Capacity, Dynamic Evaluation, Grey Prediction Model, Xiangtan

\section{Introduction}

The correlation between the global economic development and energy consumption has been increasingly important since the Industrial Revolution, thus causing a series of ecological environmental problems. The carbon emission studies caused by fossil energy consumption have been widely concerned by scholars. The dynamic changes and influencing factors of regional energy ecological footprint can provide theoretical foundation on sustainable development of ecological environment — society ecology.

Energy ecological footprint is a derivative concept of ecological footprint [1] just like land footprint [2, 3], water footprint [4], pollution footprint [5], and carbon footprint [6], etc. Energy ecological footprint converts energy consumption into biological productive land area for quantitative analysis of the relation between energy consumption and ecological environment, so as to provide the scientific foundation for policy fabrication [7]. There are abundant domestic and overseas studies on energy ecological footprint which ranges from municipal scale [8] to provincial scale [9] and national scale $[10,11]$, The results of different researches on the scales of energy footprint show that the pressure of the ecological environment on the energy footprint increases gradually, and the pressure on economically developed regions is higher than that of economically underdeveloped regions. Research methods involve in input - output models $[12,13]$, ecological footprint model [14], energy footprint model [15], and STIRPAT resource and environment economic model [16], etc. In addition, it also contains 
ecological environment, social and economic structures. Moreover, with the increase of the energy consumption, the energy ecological footprint pressure is increased gradually. Now people pay more attention to low energy, low-carbon discharge technology and industrial development $[17,18]$.

Energy ecological footprint (EEF) is an important evaluation indicator and method to analyze the relationship between regional economic development and resources-environment. Dynamic change analysis of EEF and its influencing factors, would provide a theoretical basis for sustainable development of social-economic and resources environment. In this paper, EEF calculation method and STIRPAT model has been used to explore the regional energy ecological footprint and its influencing factors and to predicte the future tendency of the energy ecological footprint. We choose Xiangtan as a representative case study.

\section{Research Methods and Data}

\subsection{Energy Ecological Footprint and Ecological Capacity}

The calculation of ecological footprint (EF) converts human consumption of various resources and energy into fossil energy land, arable land, forest, pasture, built-up areas and sea, etc., which may have ecological productivity. As a leading factor, the energy ecological footprint has the larger proportion in ecological footprint. Ecological capacity means that forestry land discharges $\mathrm{CO}_{2}$, while absorbing fossil energy. Therefore, energy ecological footprint [15], ecological footprint [14], and energy capacity [19] are chosen in the paper to be used as important indexes to analyze the sustainable utilization of regional natural resources. The computing formulas are shown as follows respectively:

$$
\begin{gathered}
E F=\sum_{j=1}^{i=1} E F_{j} \times Y F_{j} \times\left(F_{i} / Y_{i}\right) / P \\
E E F=\sum_{i=1} \frac{F_{i} \times K}{A_{i} \times 10^{6} \times P} \\
E C=\sum_{j=1} A_{j} \times E F_{j} \times Y F_{j}
\end{gathered}
$$

Where EF, EEF and EC are ecological footprint, energy ecological footprint, and energy capacity respectively, with the unit of $\mathrm{ghm}^{2}$ per person; $\mathrm{F}_{\mathrm{i}}$ is the consumption quantity of $i^{\text {th }}$ energy (Kgce); $i$ is the category of energy consumption; $j$ is land type; $\mathrm{K}$ is the thermal energy generated by standard coal $(\mathrm{KJ})$, in the study of Chen Chengzhong [18], the thermal energy generated is $7000 \mathrm{kcal}$ for $1 \mathrm{~kg}$ standard coal, $1 \mathrm{kcal}=4.1868 \mathrm{KJ} ; \mathrm{A}_{\mathrm{i}}$ is the global mean footprint of energy consumption $\left(\mathrm{ghm}^{2}\right) . \mathrm{EF}_{\mathrm{j}}$ is the equilibrium factor which is valued as 1.41 in the study of M. C. Liu [20]; YF $F_{j}$ for output factor which is valued as 0.91 in the study of Y. Z. Song [21]; $\mathrm{Y}_{\mathrm{i}}$ for the mean productivity of $\mathrm{i}^{\text {th }}$ land; $\mathrm{P}$ is regional population scale; and $\mathrm{A}_{\mathrm{j}}$ is the overall area of $\mathrm{j}^{\text {th }}$ land.

On the computing foundation of ecological footprint and ecological capacity, ecological pressure (namely the specific value between energy ecological footprint and energy capacity, presented as EPIEF) of energy ecological footprint, energy ecological footprint deficit and surplus per capita, strength of energy ecological footprint (energy ecological footprint required by GDP consumption energy at $10^{4} \mathrm{CNY}$ GDP) are applied to further evaluate sustainable continuity. The computing formula is shown as follows:

$$
E P I E F=E E F / E C \quad \& \quad E D(E S)=E E F-E C
$$

The ecological pressure of the energy ecological footprint is the direct basis for judging human and land coordination and ecological sustainable development. The larger the specific value between the energy ecological footprint and the energy capacity is, the larger the ecological environmental disruption of human activities will be, thus the larger the ecological pressure will be and it will be in deficit (ED), vice versa (ES). There is an index for evaluating the ecological safety and can be used for displaying the degree of influence of the energy consumption on the natural ecosystem.

$$
E F I=E E F / D
$$

Where, EFI is the energy footprint intensity $\left(\mathrm{ghm}^{2} / 10^{4} \mathrm{CNY}\right)$; EEF is energy efficient football ( $\mathrm{ghm}^{2} /$ person), D is the GDP per capita $\left(10^{4} \mathrm{CNY} /\right.$ person).

\subsection{Energy Ecological Footprint GM $(1,1)$ Grey Prediction Model}

In order to better predict the dynamic tendency of the energy ecological footprint in the future, $\operatorname{GM}(1,1)$ grey prediction model can be further constructed according to previous computing results of energy ecological footprint. Grey prediction is a method for predicting uncertain factors in the system [22]. A correlation analysis is conducted by identifying alien degree of development tendency between factors. Original data are disposed to look for systematic changes and to generate data sequences with strong disciplines. Afterwards, a corresponding differential equation model is constructed to predict future development tendency.

In this paper, grey model GM $(1,1)$ is established to take 5 observational values and to generate observational series:

$$
X^{(0)}=\left\{X^{(0)}(1), X^{(0)}(2), X^{(0)}(3), X^{(0)}(4), X^{(0)}(5)\right\}
$$

The new series $\mathrm{X}$ is formed through accumulation $\mathrm{X}^{(1)}$ :

$$
X^{(1)}=\left\{X^{(1)}(1), X^{(1)}(2), X^{(1)}(3), X^{(1)}(4), X^{(1)}(5)\right\}
$$

Where, $\quad X^{(1)}=X^{(1)}(1)=X^{(1)}(i-1)+X^{(1)}(i), \quad i=2,3, \ldots .5$; matrix $\mathrm{B}$ and data vector $\mathrm{Y}$ are construction with the equation as follows: 


$$
B=\left[\begin{array}{cc}
-\frac{1}{2}\left[X^{(1)}(1)+X^{(1)}(2)\right] & 1 \\
-\frac{1}{2}\left[X^{(1)}(2)+X^{(1)}(3)\right] & 1 \\
-\frac{1}{2}\left[X^{(1)}(3)+X^{(1)}(4)\right] & 1 \\
-\frac{1}{2}\left[X^{(1)}(4)+X^{(1)}(5)\right] & 1
\end{array}\right], \quad Y=\left[\begin{array}{l}
X(0)(2) \\
X(0)(3) \\
X(0)(4) \\
X(0)(5)
\end{array}\right]
$$

Corresponding differential of $\operatorname{GM}(1,1)$ grey model is shown as:

$$
\frac{d x^{(1)}}{d t}+a x^{(1)}=\mu^{(1)}
$$

Parameter vector to be estimated is set up as: $\hat{u}=\left(\begin{array}{c}\hat{a} \\ \hat{\mu}\end{array}\right)$, the minimal multiplier method is used to obtain $\hat{u}=\left(B^{T B}\right)^{-1} B^{T} Y$. By solving the differential equation, the prediction model of energy ecological footprint can be obtained:

$$
X^{(1)}(k+1)=\left[X^{(1)}(1)-\frac{\hat{\mu}}{\hat{a}}\right] e^{-\hat{a}} k+\frac{\hat{\mu}}{\hat{a}} \quad \mathrm{k}=(0,1,2, \ldots . \mathrm{n})
$$

\subsection{The Driving Factor Analysis of Energy Ecological Footprint}

From the perspective of systematic dynamics, the energy consumption level can be measured through energy ecological footprint. Changing the consumption level is the common results of regional population scale, economic level, industrial structure and energy utilization technologies [23, 24], etc. By referring to the multi-variable non-linear influencing factor of STIRPAT, the relational measurement model for influencing factors of regional energy consumption is constructed. The functional relation and mathematical model are shown as follows:

$$
Q=K P^{a_{1}} D^{a_{2}} I^{a_{3}} T^{a_{4}}
$$

where, Q is the energy ecological footprint per capita ( $\mathrm{ghm}^{2} /$ person); $\mathrm{K}$ is constant; $\mathrm{P}, \mathrm{D}, \mathrm{I}$ and $\mathrm{T}$ are population scale $\left(10^{4}\right.$ person $)$, GDP per capita $\left(10^{4} \mathrm{CNY} /\right.$ person $)$, proportion of secondary industry (\%), and energy intensity $\left(\mathrm{t} / 10^{4} \mathrm{CNY}\right) . \mathrm{a}_{1}, \mathrm{a}_{2}, \mathrm{a}_{3}$ and $\mathrm{a}_{4}$ are its elastic coefficient, respectively. When $\mathrm{P}, \mathrm{D}, \mathrm{I}$ and $\mathrm{T}$ changes $1 \%$, it will cause the changes of $Q$ for $a_{1} \%, a_{2} \%, a_{3} \%$ and $a_{4} \%$.

To take the logarithm in the Formula (10), it can obtain:

$$
\operatorname{In}(Q)=\operatorname{In}(K)+a_{1} \operatorname{In}(P)+a_{2} \operatorname{In}(D)+a_{3} \operatorname{In}(I)+a_{4} \operatorname{In}(T)
$$

Where, $\operatorname{In}(Q)$ is dependent variable; $\operatorname{In}(P), \operatorname{In}(D)$, $\operatorname{In}(I), \operatorname{In}(T)$ are independent variables, and $\operatorname{In}(K)$ is constant, with multiple linear regression analysis, relevant parameters can be confirmed.

\subsection{Data Source}

The original data used in this study mainly come from Xiangtan Statistic Yearbook over the years and "the $11^{\text {th }}$ Five-year Plan", and "the $12^{\mathrm{h}}$-year Plan" in Xiangtan, With

\begin{tabular}{|c|c|c|c|c|c|c|c|c|c|c|}
\hline Energy consumption $\left(F_{i}\right)$ & 2006 & 2007 & 2008 & 2009 & 2010 & 2011 & 2012 & 2013 & 2014 & 2015 \\
\hline Raw coal & 1134711 & 1221450 & 1284514 & 1471054 & 1741950 & 1791845 & 1691040 & 1758992 & 1955220 & 2422105 \\
\hline Cleaned coal & 0 & 0 & 0 & 176217 & 201017 & 327389 & 327834 & 261636 & 261642 & 264767 \\
\hline Coke & 2687 & 8540 & 11903 & 81 & 29410 & 10659 & 17875 & 21891 & 19951 & 24848 \\
\hline Kerosene & 212 & 486 & 379 & 22 & 321 & 362 & 420 & 409 & 115 & 61 \\
\hline Diesel & 11989 & 11633 & 16827 & 142 & 17804 & 20348 & 24281 & 26012 & 18179 & 16375 \\
\hline Fuel oil & 0 & 0 & 0 & 3587 & 2145 & 22670 & 19287 & 2311 & 931 & 735 \\
\hline $\operatorname{Gas}\left(10^{4} \mathrm{~m}^{3}\right)$ & 0 & 0 & 0 & 0 & 5857 & 7047 & 7401 & 10505 & 11468 & 13449 \\
\hline Thermal $\left(10^{6} \mathrm{KJ}\right)$ & 314437 & 483695 & 651308 & 38 & 495553 & 4606932 & 4572413 & 4518290 & 4465204 & 4349312 \\
\hline Electricity $\left(10^{4} \mathrm{KWh}\right)$ & 136065 & 143647 & 150579 & 174849 & 150388 & 132974 & 143654 & 157586 & 187129 & 475878 \\
\hline Regional population $(\mathrm{P})$ & 282 & 283 & 284 & 291.64 & 292.7 & 293.99 & 295.26 & 289 & 276.45 & 291.8 \\
\hline GDP per person (D) & 5855 & 6847 & 7773 & 8687 & 10388 & 12219 & 14402 & 17693 & 21608 & 24650 \\
\hline Second Industry proportion (I) & $42.12 \%$ & $43.85 \%$ & $44.94 \%$ & $45.56 \%$ & $46.65 \%$ & $51.60 \%$ & $52.44 \%$ & $58.82 \%$ & $60.24 \%$ & $62.58 \%$ \\
\hline Energy intensity $(\mathrm{T})$ & 2.90 & 1.70 & 1.60 & 20 & 1.50 & 1.360 & 1.14 & 1.02 & 0.80 & 0.77 \\
\hline Regional land area (A) & 279 & 279 & 279 & 279 & 279 & 279 & 279 & 658 & 658 & 658 \\
\hline
\end{tabular}
energy consumption data, population scale and economic scale, a secondary treatment on data is conducted to obtain basic data in Table 1 .

Table 1. Original Data of Energy Consumption, Population and Economic Scale from 2006 to 2015 in Xiangtan.

\section{Results and Discussion}

\subsection{Dynamic Changes of Energy Ecological Footprint, Ecological Footprint and Ecological Capacity}

The energy ecological footprint, the ecological footprint, the ecological capacity, the ecological deficit (surplus) and the ecological strength are calculated to evaluate the ecological sustainability of the regional development through Eq. (1)-Eq. (3) and Eq. (5):

(1) Energy ecological footprint: The figure 1 show that energy ecological footprint in Xiangtan presents an increasing tendency year by year, indicating 
$0.3435 \mathrm{ghm}^{2} /$ person in 2015 compared to $0.1234 \mathrm{ghm}^{2} /$ person in 2006. Until 2008, the absolute amount of energy ecological footprint per capita was lower than the mean of $0.132343 \mathrm{ghm}^{2} /$ person. The rising proportion was lower and the annual mean increase was $3.84 \%$. From 2009 to 2011 , it was greatly improved with the mean of $0.2041 \mathrm{ghm}^{2} /$ person and it was 1.54 times the mean in 2006-2008. It was the middle rising period of amplitude, and the mean annual growth was $33.84 \%$. In 2009, guided by the national policy, Xiangtan joined the Wan-jiang urban belt to speed up the industrial transfer, to urbanize Xiangtan and to keep the footprint in Xiangtan in the deficit state. The level was increased to $0.2504 \mathrm{ghm}^{2}$ per capita in 2015 from $0.073 \mathrm{ghm}^{2}$ per capita in 2006 . The energy ecological footprint pressure presented an increasing tendency in general. It was increased to 3.6834 times in 2013 from 2.45 times in 2006. It shows that the energy consumption in Xiangtan has had a large influences on the environment since 2006 and it has been seriously unsustainable. With lower ecological safety level and higher ecological risks, it must transfer to energy intensive utilization from energy extensive utilization to develop the industry rapidly. The natural energy consumption will be enlarged, while developing the economy, thus the energy economic footprint per capita will be enlarged along with it. In 2012, the country greatly implemented sustainable development strategies and carried out scientific outlook on the development, thus the energy ecological footprint per capita started to present a downtrend. After 2013, the country started to implement the energy conservation and some emission reduction policies on large-scale enterprises and SMES, requesting them to strictly obey the relevant laws of environmental protection, implementing incentives on enterprises, and punishment systems, improving the efficient utilization of resources, conducting clean productions, and greatly promoting sustainable development strategies. Because the economic development couldn't avoid energy consumptions, the energy ecological footprint per capita continued to present a rising tendency.

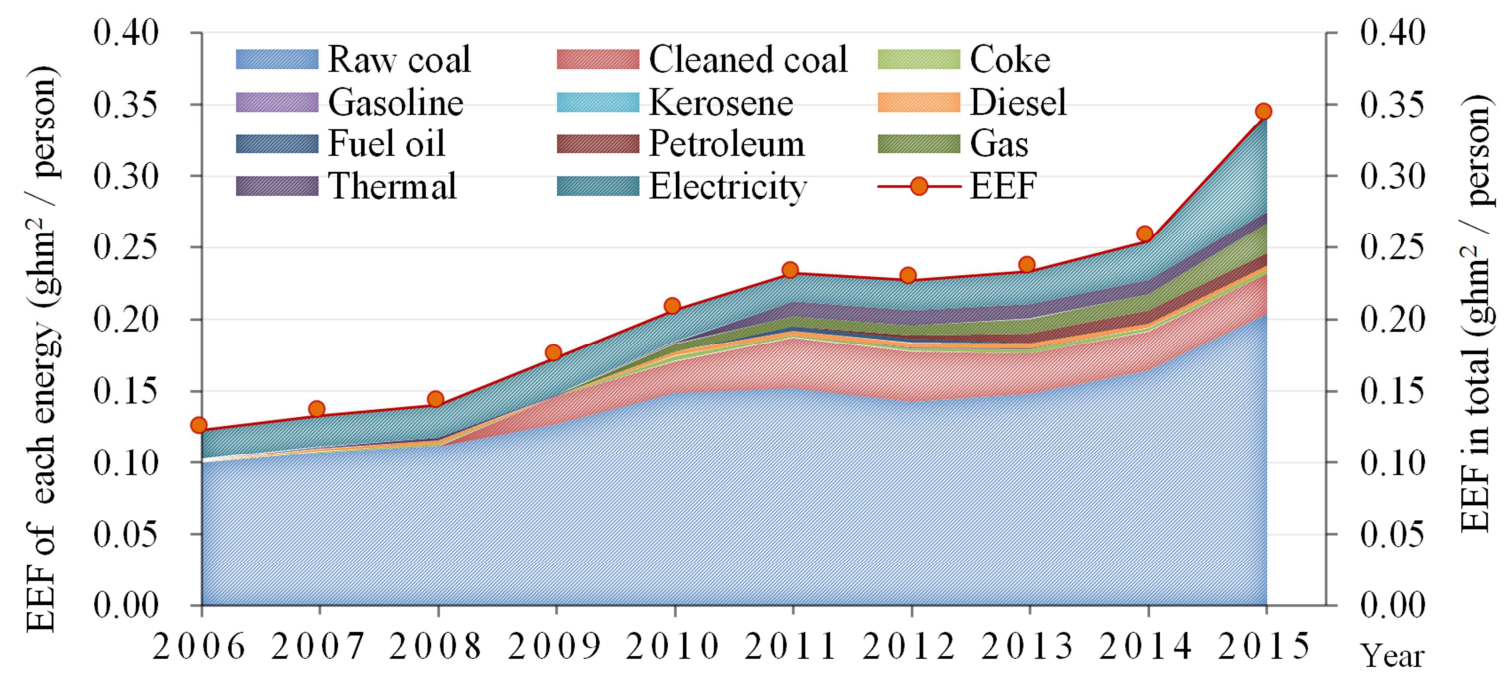

Figure 1. The change of Energy Ecological Footprint from 2006-2015.

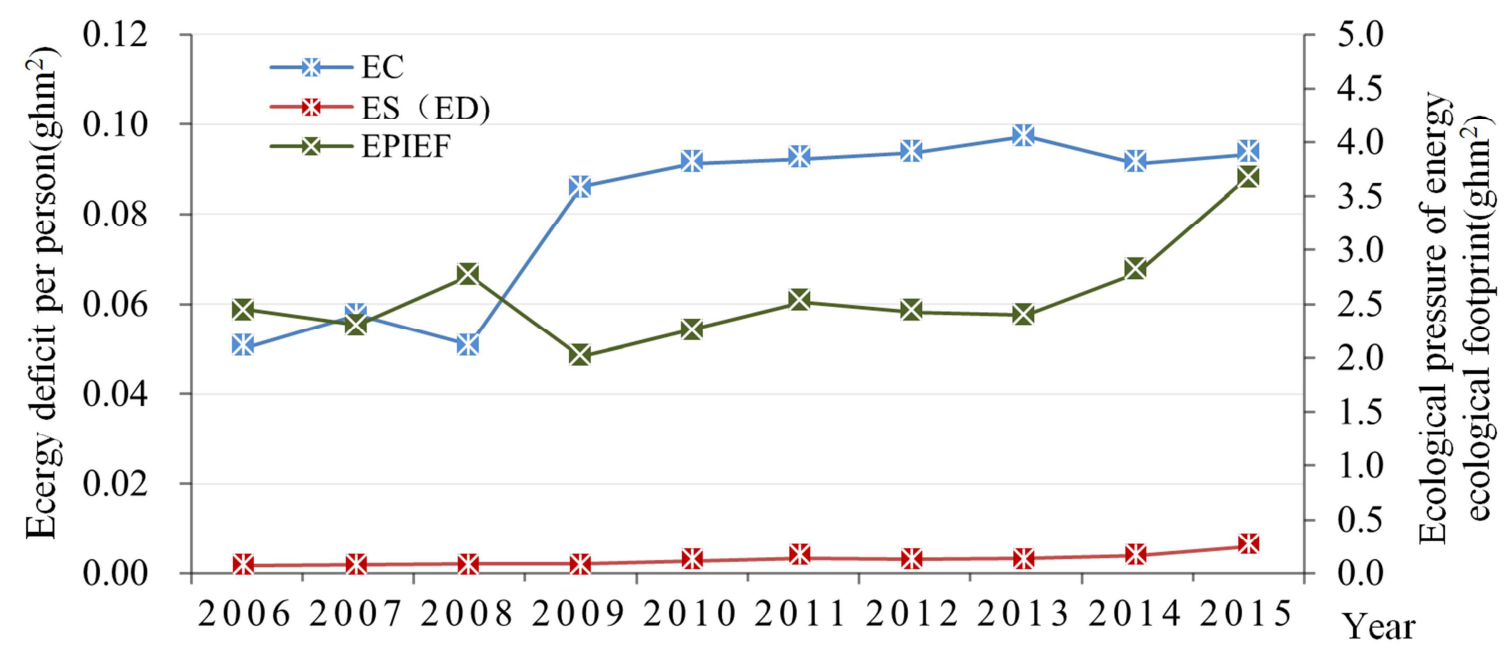

Figure 2. Change of energy capacity and ecological pressure of energy ecological footprint from 2006-2015. 


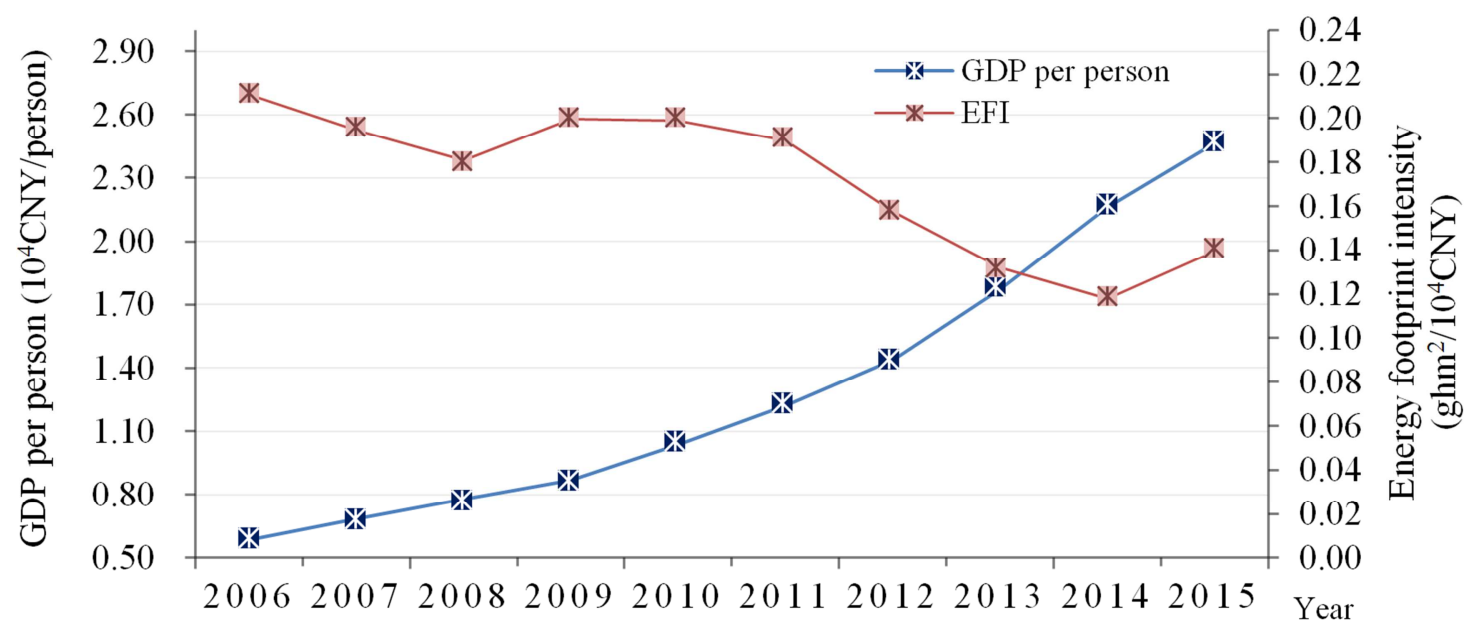

Figure 3. Chang of GDP per person and energy footprint intensity from 2006 to 2015.

(2) Ecological pressure analysis of energy ecological footprint: The figure 2 show that capacity of energy ecological footprint per capita had the larger fluctuation before 2009. In 2009-2013, it presented the weak increasing tendency, but it started to reduce afterwards. To sum up, per capita was increased to $0.0933 \mathrm{ghm}^{2}$ in 2015 from $0.0504 \mathrm{ghm}^{2}$ in 2003. Energy economic footprint per capita was greater than energy capacity per capita, indicating that energy ecological footprint in Xiangtan has been kept in the deficit state. The level was increased to $0.2504 \mathrm{ghm}^{2}$ per capita in 2015 from $0.073 \mathrm{ghm}^{2}$ per capita in 2006 . The energy ecological footprint pressure presented the increasing tendency as a whole. It was increased to 3.6834 times in 2015 from 2.45 times in 2006, showing that energy consumption in Xiangtan has had the large influences on the environment since 2006 and it has been serious unsustainable. With lower ecological safety level and higher ecological risks, it must transfer to energy intensive utilization from energy extensive utilization.

(3) Energy ecological footprint intensity: From 2006 to 2015, GDP per capita in Xiangtan presented the rising tendency in a straight line. It was increased to 24650 $\mathrm{CNY} /$ person in 2015 from $5855 \mathrm{CNY} /$ person in 2006 and it was increased by 4 times. However, energy ecological footprint intensity presented downtrend. The decreasing amplitude was $14.26 \%$, but it only had a little recovery between 2008 and 2009 (Figure 3). In recent years, under the background of loose national macroscopic capacity policy and weak industrial foundation in Xiangtan, the government loosened the access threshold of high energy consumption, high discharge and low-efficient enterprises. These enterprises have lagging devices and poor production performance, so they consumed lots of resources and energy, resulting in rising GDP constantly, but reducing its strength continuously.

\subsection{Dynamic Analysis of Energy Ecological Footprint and Ecological Capacity}

Though grey prediction model differential equation formula and model Eq. (10), energy ecological footprint per capital in Xiangtan over the years and its energy capacity per capita can be calculated, obtaining the predictive equations of them, respectively:

$$
\begin{gathered}
X^{(1)}(k+1)=1.288022 e^{-0.15} k-1.055907 \\
X^{(1)}(k+1)=6.609213 e^{-0.002} k-6.517
\end{gathered}
$$

Through Eq. (13) and Eq. (14) and Eq. (4), it can be predicted the energy ecological footprint per capita, energy capacity per capita and dynamic supply and demand changes of energy ecological footprint in Xiangtan from 2017 to 2025 can be predicted in Table2.

\begin{tabular}{|c|c|c|c|c|c|c|c|c|c|}
\hline & 2017 & 2018 & 2019 & 2020 & 2021 & 2022 & 2023 & 2024 & 2025 \\
\hline Energy Ecological Footprint (EEF) & 0.3801 & 0.4413 & 0.5127 & 0.5957 & 0.6921 & 0.8041 & 0.9319 & 1.0854 & 1.1205 \\
\hline energy capacity (EC) & 0.1110 & 0.1244 & 0.1244 & 0.1245 & 0.1245 & 0.1245 & 0.1245 & 0.1246 & 0.1246 \\
\hline Ecological pressure (EPIEF) & 3.4227 & 3.5470 & 4.1201 & 4.7858 & 5.5592 & 6.4574 & 7.5082 & 8.7128 & 8.9013 \\
\hline
\end{tabular}

Table 2. Dynamic Prediction of Energy Ecological Footprint from 2017 to 2025.

Energy ecological footprint per capita in the area has been increased dramatically since 2017 . It will be increased to $1.1205 \mathrm{ghm}^{2} /$ person in 2025 from $0.3801 \mathrm{ghm}^{2} /$ person in 2017 . It will be increased by 3 times within 7 years. The energy capacity per capita will basically maintain relevant stable without obvious changes. In the ecological pressure of energy economic footprint, the specific value between energy ecological footprints per capital will be increased to 8.9013 in 2025 from 3.4227 in 2017 . The ecological pressure is very large. In other words, supply and demand balance of ecology has been deficient.

\subsection{Driving Factor Analysis of Energy Economic Footprint}

According to relational measurement model of regional 
energy consumption footprint, influences of GDP per capita, industrial structure, energy strength, and population scale on energy ecological footprint per capita are analyzed. The least square method in SPSS is applied to do regression fitting and to obtain the following equation:

Regression results indicate that $\mathrm{R}^{2}=0.918, \mathrm{~F}=13.955, \mathrm{p}$ ( $\mathrm{sig}$ ) value is $0.006<0.01$, indicating that the model fitting effects are obvious. The fitting equation results show that population scale, GDP per capita, industrial structure and energy intensity have the elastic coefficients of $0.372,0.338,1.007$ and 0.215 , respectively, indicating that population scale, GDP per capita, industrial structure and energy intensity are changed for $1 \%$. It will make energy ecological footprint per capita be increased by $0.372 \%, 0.338 \%, 1.007 \%$ and $0.215 \%$, showing that industrial structure has the most obvious influences on energy ecological footprint per capita, followed by population scale and GDP per capita, and the minimal energy utilization.

\section{Conclusions}

Energy is the driving force of the economic development and also the main source of $\mathrm{CO}_{2}$ discharge. By estimating the energy ecological footprint per capita, the ecological capacity per capita, and ecological pressure of the energy ecological footprint in Xiangtan over the years, the changing tendency of each index in the next 10 years could be predicted, based on the grey prediction model. The results show that regional energy ecological footprint in Xiangtan presents a rising tendency year by year. The specific value between the energy ecological footprint and the ecological capacity will be enlarged year by year during the next 10 years. The value exceeded 8 , indicating that regional ecological environment has a huge pressure. The influencing factors of energy ecological footprint per capita, industrial structure and population scale are the most significant and the main driving factors of the energy economic footprint per capita.

As a result, on the one hand, the regional energy development in Xiangtan should utilize the natural resource advantages, promote a clean production and a circular economic strategy in multiple aspects, allocate resources rationally and take full advantage of clean resources, and efficiently improve in resource utilization. On the other hand, it can adjust and optimize the regional industrial structure, transform the economic development mode, improve the economic growth quality, and abandon the unsustainable development model for economic growth. Then, it must control the population growth rate and finally achieve the goal of realizing a coordinative development in population, energy and environment.

\section{Acknowledgements}

We would like to thank you two support departments: the National Natural Science Foundation of China, science fund 51478470 entitled "Research on spatial planning of low-carbon city of new district based on the carbon emission scenario model" and "Thirteenth Five-Year Plan" Key Subject Funding Project of China State Forestry Administration under grant NO. 44 [2015].

\section{References}

[1] W. E. Rees, "Ecological footprint and appropriated carrying capacity: what urban economics leaves out," Environment and Urbanization. 4 (2): 121-130 (1992).

[2] K. Fang, R. Heijungs, Z. Duan, et al., "The Environmental Sustainability of Nations: Benchmarking the Carbon, Water and Land Footprints against Allocated Planetary Boundaries," Sustainability. 7: 11285-11305 (2015).

[3] H. H. Khoo, "Review of bio-conversion pathways of lignocellulose-to-ethanol: sustainability assessment based on land footprint projections," Renewable \& Sustainable Energy Reviews. 46: 100-119 (2015).

[4] E. Matthew, "The Water Footprint Assessment Manual Setting the Global Standard," Social \& Environmental Accountability Journal. 31 (2): 181-182 (2011).

[5] Q. W. Min, W. J. Jiao, S. K. Cheng, "Pollution Footprint: A Type of Ecological Footprint Based on Ecosystem Services," Resources Science. 33 (2): 195-200 (2011).

[6] B. P. Weidema, M. Thrane, P. Christensen et al., "Carbon Footprint," Journal of Industrial Ecology. 12 (1): 3-6 (2008).

[7] J. J. Ferng, "Toward a scenario analysis framework for energy footprints," Ecological Economics. 40 (1): 53-69 (2002).

[8] M. A. Luck, G. D. Jenerette, J. Wu et al., "The Urban Funnel Model and the Spatially Heterogeneous Ecological Footprint," Ecosystems. 4 (8): 782-796 (2001).

[9] T. Okadera, Y. Geng, T. Fujita et al., "Evaluating the water footprint of the energy supply of Liaoning Province, China: A regional input-output analysis approach," Energy Policy. 78 (C): 148-157 (2015).

[10] C. Z. Chen, Z. S. Lin, "Multiple timescale analysis and factor analysis of energy ecological footprint growth in China 19532006," Energy Policy. 36 (5): 1666-1678 (2008).

[11] A. C. Penela, C. S. Villasante, "Applying physical inputoutput tables of energy to estimate the energy ecological footprint (EEF) of Galicia (NW Spain)," Energy Policy. 36 (3): 1148-1163 (2008).

[12] S. Gabriele, S. Moana et al., "Estimating the human appropriation of land in Brazil by means of an Input-Output Economic Model and Ecological Footprint analysis," Ecological Indicators. 53 (6): 78-94 (2015).

[13] Z. Wang, Y. Li, Z. H. Li et al., "An analysis of Carbon Footprint of Beijing Based on Input-output Model," International Conference on Advances in Energy and Environmental Science. 1052-1058 (2013).

[14] V. Niccolucci, A. Galli, A. Reed et al., "Towards a 3D National Ecological Footprint Geography,” Ecological Modelling. 222 (16): 2939-2944 (2011).

[15] G. Stöglehner, "Ecological footprint—a tool for assessing sustainable energy supplies," Journal of Cleaner Production. 11 (3): 267-277 (2003). 
[16] D. Hummel, S. Adamo, A. D. Sherbinin et al., "Inter and transdisciplinary approaches to population-environment research for sustainability aims: a review and appraisal," Population \& Environment. 34 (4): 481-509 (2012).

[17] M. Wackernagel, W. E. Rees, "Our Ecological Footprint: Reducing Human Impact on the Earth," Population \& Environment. 1 (3): 171-174 (1998).

[18] C. Z. Chen, Z. S. Lin, "Driving forces analysis of energy ecological footprint growth fluctuation in China," Acta Ecologica Sinica. 29 (2): 758-767 (2009).

[19] S. Y. Cao, G. D. Xie, "Evolvement of ecological footprint model representing ecological carrying capacity," Chinese Journal of Applied Ecology. 18 (6): 1365-72 (2007).

[20] M. C. Liu, B. Wang, W. H. Li, "Analysis and Dynamic Prediction of China's Development Based on the Ecological Footprint Method," Resources Science. 32 (1): 163-170 (2012).
[21] Y. Z. Song, B. P. Han, "Dynamic Analysis of Ecological Footprint and Its Forecast Based on GM $(1,1)$ in Coal Mining Area-An Case Study of Huaibei," International Symposium on Geo-Environmental Engineering for Sustainable Development. 01: 113-118 (2007).

[22] L. M. Wang, K. L. He, "Analysis of spatial variations in environmental impact based on the STIRPAT model - a case study of energy consumption," Acta Scientiae Circumstantiae. 28 (5): 1032-1037 (2008).

[23] S. C. Chang, W. T. Huang, "The Effects of Foreign Direct Investment and Economic Development on Carbon Dioxide Emissions," Econometrics of Risk. 583: 483-496 (2015).

[24] M. Kissinger, Y. Karplus, "IPAT and the analysis of local human-environment impact processes: the case of indigenous Bedouin towns in Israel," Environment, Development and Sustainability. 17 (1): 101-121 (2015). 